\title{
Reference intervals of salivary cortisol and cortisone and their diagnostic accuracy in Cushing's syndrome
}

\author{
Nils Bäcklund1', Göran Brattsand², Marlen Israelsson², Oskar Ragnarsson ${ }^{3,4}$, Pia Burman, Britt Edén Engström6 \\ Charlotte Høybye ${ }^{7}$, Katarina Berinder ${ }^{7}$, Jeanette Wahlberg ${ }^{8}$, Tommy Olsson ${ }^{1}$ and Per Dahlqvist ${ }^{1}$
}

${ }^{1}$ Department of Public Health and Clinical Medicine, Umeå University, Umeå, Sweden, ${ }^{2}$ Department of Medical Biosciences, Clinical Chemistry, Umeå University, Umeå, Sweden, ${ }^{3}$ Department of Internal Medicine and Clinical Nutrition, Institute of Medicine at Sahlgrenska Academy, University of Gothenburg, Gothenburg, Sweden, ${ }^{2}$ Department of Endocrinology, Sahlgrenska University Hospital, Gothenburg, Sweden, ${ }^{5}$ Department of Endocrinology, Skåne University Hospital, University of Lund, Malmö, Sweden, ${ }^{6}$ Department of Medical Sciences, Endocrinology and Mineral Metabolism, Uppsala University, Uppsala, Sweden, ${ }^{7}$ Department of Molecular Medicine and Surgery, Patient Area Endocrinology and Nephrology, Inflammation and Infection Theme, Karolinska Institute and Karolinska University Hospital, Stockholm, Sweden, and ${ }^{8}$ Department of Endocrinology, Department of Medical and Health Sciences, Linköping University, Linköping, Sweden

Correspondence should be addressed to $N$ Bäcklund Email

nils.backlund@umu.se

\begin{abstract}
Objective: The challenge of diagnosing Cushing's syndrome (CS) calls for high precision biochemical screening. This study aimed to establish robust reference intervals for, and compare the diagnostic accuracy of, salivary cortisol and cortisone in late-night samples and after a low-dose $(1 \mathrm{mg})$ dexamethasone suppression test (DST).

Design and methods: Saliva samples were collected at 08:00 and 23:00 h, and at 08:00 h, after a DST, from 22 patients with CS and from 155 adult reference subjects. We also collected samples at 20:00 and 22:00 h from 78 of the reference subjects. Salivary cortisol and cortisone were analysed with liquid chromatography-tandem mass spectrometry. The reference intervals were calculated as the 2.5th and 97.5th percentiles of the reference population measurements. Diagnostic accuracies of different tests were compared, based on areas under the receiver-operating characteristic curves.

Results: The upper reference limits of salivary cortisol and cortisone at $23: 00 \mathrm{~h}$ were $3.6 \mathrm{nmol} / \mathrm{L}$ and $13.5 \mathrm{nmol} / \mathrm{L}$, respectively. Using these reference limits, CS was detected with a sensitivity $(95 \% \mathrm{Cl})$ of $90 \%(70-99 \%)$ and specificity of $96 \%$ (91-98\%) for cortisol, and a 100\% (84-100\%) sensitivity and 95\% (90-98\%) specificity for cortisone. After DST, cortisol and cortisone upper reference limits were $0.79 \mathrm{nmol} / \mathrm{L}$ and $3.5 \mathrm{nmol} / \mathrm{L}$, respectively. CS was detected with $95 \%$ (75-100\%) sensitivity and 96\% (92-99\%) specificity with cortisol, and 100\% (83-100\%) sensitivity and 94\% (89-97\%) specificity with cortisone. No differences in salivary cortisol or cortisone levels were found between samples collected at 22:00 and 23:00 h.

Conclusion: Salivary cortisol and cortisone in late-night samples and after DST showed high accuracy for diagnosing CS, salivary cortisone being slightly, but significantly better.
\end{abstract}

European Journal of Endocrinology

(2020) 182, 569-582
Published by Bioscientifica Ltd. 


\section{Introduction}

Diagnosis of Cushing's syndrome (CS) is still a major challenge in clinical endocrinology, relying on the combination of clinical signs and biochemical tests of hypercortisolism. Currently, the recommended biochemical screening methods for CS include over-night low-dose $(1 \mathrm{mg})$ dexamethasone suppression test (DST); 24-hour urinary free cortisol (UFC); or late-night salivary cortisol (LNSC). All of these methods have pros and cons (1). Advantages of salivary cortisol are the simple sampling procedure, close correlation with free plasma cortisol levels, and independence from variations in plasma cortisol-binding globulin (CBG) $(2,3,4)$. Furthermore, the LNSC is not hampered by variations in dexamethasone metabolism. The DST evaluates the suppressibility of the hypothalamic-pituitary-adrenal (HPA) axis; that is, a low plasma cortisol in the morning, after taking oral dexamethasone, excludes CS. The conventional DST depends on plasma cortisol analysis, which requires a venous blood sample and is affected by differences in plasma CBG levels, for example, in women using estrogen containing oral contraceptives (OCs) (1).

During the passage from blood to saliva, most of the cortisol is converted into cortisone in the salivary gland by the enzyme $11 \beta$-hydroxysteroid dehydrogenase type 2 (11ß-HSD2). Thus, in saliva, cortisol and cortisone are present in a 1:5 ratio, compared to the 5:1 ratio in blood $(5,6,7,8,9)$. Knowledge of the normal salivary cortisol:cortisone ratio can be used to detect contamination from blood or exogenous hydrocortisone, although the normal range (reference interval) remains to be established $(5,8,9,10,11,12,13,14)$. Alternatively, measuring salivary cortisone, instead of cortisol, might reduce problems associated with contamination. Moreover, it has been suggested that plasma free cortisol levels correlate better with salivary cortisone than with salivary cortisol $(3,15)$. However, to ensure the clinical usefulness of measuring salivary cortisone for diagnosing CS with current methods, we need to determine robust reference intervals, diagnostic cut-off levels, and diagnostic accuracy for samples collected both late at night and after $\operatorname{DST}(3,15,16,17,18)$.

Analysing salivary glucocorticoids with liquid chromatography-tandem mass spectrometry (LC-MS/ MS) has the advantage of high specificity, compared to immunoassays. LC-MS/MS also allows simultaneous measurements of salivary cortisol and cortisone, and it has a low limit of quantification. Importantly, as the use of LC-MS/MS increases, solid reference intervals are needed for determining the diagnostic accuracy of CS screening tests.

The present study aimed to establish robust reference intervals for salivary cortisol and cortisone, sampled at 08:00 h, 23:00 h, and after DST, measured with LC-MS/ MS; to calculate the sensitivity and specificity of these tests for correctly identifying patients with CS; and to compare the diagnostic accuracies of different tests. We also aimed to test whether a combined test, with salivary samples collected both late at night and after DST, might be superior to a single test; to establish the normal salivary cortisol:cortisone ratio; and to evaluate the effects of gender, oestrogen status, age, tobacco use, season, and different evening sampling times.

\section{Methods}

\section{Participants}

In accordance with the Clinical and Laboratory Standards Institute (CLSI) approved guidelines for establishing reference intervals we aimed to prospectively include at least 153 reference individuals to be able to calculate the 2.5th and 97.5th percentiles with $95 \%$ confidence limits (19). The reference group of men and women over 18 years of age was recruited from Umeå, Sweden, through advertisements at the hospital, university, primary health care centres, local newspapers, and social media. Exclusion criteria were known disease in the HPA axis, glucocorticoid medication during the prior 6 weeks, aberrant diurnal rhythm (awake between 24:00 and 05:30 h), fever $\left(>38^{\circ} \mathrm{C}\right)$, and severe oral problems. After providing written informed consent, reference individuals were assessed by an experienced research nurse, who administered a brief health questionnaire, measured body temperature, height, weight, waist circumference, and blood pressure, and collected capillary blood samples for hemoglobin and fasting blood glucose measurements. Potential sleep and diurnal rhythm disturbances were assessed with the insomnia severity index (ISI) (20). Participating women reported menopausal status and oestrogen use.

Of the 175 reference subjects recruited, 17 subjects were excluded, due to use of inhaled or nasal glucocorticoids $(n=4)$, severe oral problems $(n=1)$, serious illness during the sampling period $(n=1)$, missing blood samples $(n=5)$, and pregnancy $(n=6)$. Furthermore, three reference subjects with plasma cortisol $\geq 138 \mathrm{nmol} / \mathrm{L}$ after DST were excluded from the reference population, because further investigation was required to exclude CS 
Table 1 Baseline characteristics of the reference population.

\begin{tabular}{|c|c|c|c|c|}
\hline Study cohort & Women & Men & $\begin{array}{c}\text { Reference } \\
\text { population (\%) }\end{array}$ & $\begin{array}{c}\text { Patients } \\
\text { with CS (\%) }\end{array}$ \\
\hline All & 91 & 64 & $155(100)$ & $22(100)$ \\
\hline \multicolumn{5}{|l|}{ Age } \\
\hline $20-30 y$ & 24 & 14 & $38(25)$ & $1(5)$ \\
\hline $31-40 y$ & 11 & 11 & $22(14)$ & $1(5)$ \\
\hline $41-50 y$ & 22 & 12 & $34(22)$ & $8(36)$ \\
\hline $51-60 y$ & 13 & 16 & 29 (19) & $5(23)$ \\
\hline $61-70 y$ & 14 & 5 & $19(12)$ & $3(14)$ \\
\hline$\geq 71$ y & 7 & 6 & $13(8)$ & $4(18)$ \\
\hline \multicolumn{5}{|l|}{$\mathrm{BMI}$} \\
\hline$\geq 30 \mathrm{~kg} / \mathrm{m}^{2}$ & 14 & 6 & $20(13)$ & $9(41)$ \\
\hline$<30 \mathrm{~kg} / \mathrm{m}^{2}$ & 77 & 58 & $135(87)$ & $13(59)$ \\
\hline \multicolumn{5}{|l|}{ Diabetes } \\
\hline Yes & 3 & 3 & $6(4)$ & $7(32)$ \\
\hline No & 88 & 61 & $149(96)$ & $15(68)$ \\
\hline \multicolumn{5}{|l|}{ Age } \\
\hline$\geq 70 y$ & 9 & 6 & $15(10)$ & $4(18)$ \\
\hline$<70 y$ & 82 & 58 & $140(90)$ & $18(82)$ \\
\hline \multicolumn{5}{|l|}{ Tobacco use } \\
\hline Smokers & 5 & 2 & $7(5)$ & $2(9)$ \\
\hline No tobacco use & 77 & 51 & $128(83)$ & $16(73)$ \\
\hline Snus users & 9 & 11 & $20(13)$ & $4(18)$ \\
\hline \multicolumn{5}{|l|}{ ISI score } \\
\hline$\geq 15$ & 1 & 6 & $7(5)$ & $13(59)$ \\
\hline$<15$ & 90 & 58 & $148(95)$ & $6(27)$ \\
\hline \multicolumn{5}{|l|}{ Oral problems } \\
\hline Mild & 7 & 0 & $7(5)$ & $9(41)$ \\
\hline None & 84 & 64 & $148(95)$ & $13(59)$ \\
\hline \multicolumn{5}{|l|}{ Hypertension } \\
\hline Yes & 14 & 10 & $24(15)$ & $14(64)$ \\
\hline No & 77 & 54 & $131(85)$ & $8(36)$ \\
\hline
\end{tabular}

BMI, body mass index; CS, Cushing's syndrome; ISI, insomnia severity index.

(21). Of the remaining 155 included reference subjects, 13 had plasma cortisol levels of 50-137 nmol/L after DST. Baseline characteristics of the eligible reference group $(n=155)$ are presented in Table 1.

To test the sensitivity and specificity for CS using salivary cortisol and cortisone, 24 patients $>18$ years of age with a strong suspicion of CS were included at endocrine departments of five university hospitals in Sweden, during the same period of time that the reference subjects were included. Confirmed CS diagnosis including clinical and biochemical characteristics, type and severity of CS were reported by the participating endocrinologists, according to a standardized questionnaire. In two of the patients in this group CS could not be confirmed and these were therefore excluded. Thus, only patients with confirmed CS were included in the study. Characteristics of the patients with CS $(n=22)$ in the study are presented in Table 2.

This study was approved by the local Ethics Committee at Umeå University (Dnr 2015/08-31).
Table 2 Demographic characteristics of patients with

Cushing's syndrome.

\begin{tabular}{lcc}
\hline Characteristics & Patients $(n=22)$ \\
\hline Women, $n(\%)$ & & $17(77)$ \\
Age, y; mean (range) & $55(22-82)$ \\
Aetiology, $n(\%)$ & \\
Cushing's disease & $12(55)$ \\
Ectopic ACTH & $5(23)$ \\
Adrenal adenoma & $4(18)$ \\
Missing data & $1(5)$ \\
Severity, $n(\%)$ & \\
Mild & $8(36)$ \\
Moderate & $8(36)$ \\
Severe & $5(23)$ \\
Missing data & $1(5)$ \\
\hline
\end{tabular}

\section{Saliva collection}

Saliva samples were collected at participants' homes from March 2015 to April 2016. Each individual collected samples at one occasion, for two consecutive days at 08:00 h, 23:00 $\mathrm{h}$ and the next morning at 08:00 h after DST. All participants were instructed to avoid strenuous physical activity on the day of collection and the day before; to avoid smoking and snus (moist, smokeless tobacco) for 1 $\mathrm{h}$ before sampling; to avoid eating, drinking, and brushing teeth for 30 min prior to sampling; and to rinse out the mouth with water at $10 \mathrm{~min}$ prior to sampling. Saliva was collected using Salivette ${ }^{\circledR}$ Cortisol tubes (Sarstedt, Nümbrect, Germany) either by chewing on the Salivette ${ }^{\circledR}$ Cortisol swab for $1 \mathrm{~min}$ or by placing it under the tongue for $1 \frac{1}{2} \mathrm{~min}$, to allow passive saliva absorption. Each participant provided duplicate samples, at 08:00 and 23:00 $\mathrm{h}$ ( $\pm 15 \mathrm{~min})$. On the same sampling day, half the reference population also provided one saliva sample at 20:00 $\mathrm{h}$ and one at 22:00 ( $\pm 15 \mathrm{~min})$. A 1-mg dexamethasone tablet (Abcur AB, Helsingborg, Sweden) was taken at 23:00 h and on the following day, duplicate saliva samples were collected at 08:00 $\mathrm{h}( \pm 15 \mathrm{~min})$ and a venous blood sample was drawn for plasma cortisol analysis. All Salivette ${ }^{\circledR}$ tubes were frozen at $-20^{\circ} \mathrm{C}$ for at least $24 \mathrm{~h}$, then thawed and centrifuged (5 min at $2826 \boldsymbol{g}$ ). Next, the duplicate samples from each time point were pooled and stored at $-80^{\circ} \mathrm{C}$ until analysis. Saliva samples collected from patients with CS at other hospitals were sent by mail and analysed in the same batch as the samples from the reference subjects.

\section{Biochemical analysis methods}

The cortisol in saliva was quantified with LC-MS/MS, as described previously (second setup in (22)). Briefly, samples were separated with ultra-HPLC (UHPLC) on 
a Kinetex Biphenyl column. Analysis was performed with a SCIEX QTRAP 5500 LC-MS/MS system, operated with electrospray ionization in the positive ion mode. This method was previously shown to be unaffected by samples from patients treated with prednisolone or by the two endogenous cortisol isomers, $20 \alpha-$ and 20ß-dihydrocortisone. Cortisone and cortisol were analysed in the same run. Cortisone eluted at $3.47 \mathrm{~min}$; it was quantified by a transition at $\mathrm{m} / \mathrm{z} 361.2>163.2$ and confirmed at $\mathrm{m} / \mathrm{z} 361.2>121.1$. The declustering potential for cortisone was $75 \mathrm{~V}$, the collision energies were $32 \mathrm{~V}(361.2>163.2)$ and $38 \mathrm{~V}(361.2>121.1)$, and the cell exit potentials were $15 \mathrm{~V}(361.2>163.2)$ and $13 \mathrm{~V}$ (361.2>121.1). Recovery for cortisol was 78 and $79 \%$ at $5 \mathrm{nmol} / \mathrm{L}$ and $50 \mathrm{nmol} / \mathrm{L}$ respectively, and for cortisone 100 and $104 \%$ at $5 \mathrm{nmol} / \mathrm{L}$ and $100 \mathrm{nmol} / \mathrm{L}$ respectively. Deuterated cortisone- 2, 2, 4, 6, 6, 12, 12- $\mathrm{d}_{7}$ (705586, Sigma-Aldrich) and cortisol- 9, 11, 12, 12- $\mathrm{d}_{4}$ (DLM2218, Cambridge Isotope Laboratories, Larodan) were used as internal standards to compensate for recovery losses. Calibration standards were prepared in $0.1 \%$ (wt/ vol) PBS, pH 7.4, at 0, 1, 5, 20, 50, 150, and $300 \mathrm{nmol} / \mathrm{L}$, from stock solutions containing $2.76 \mathrm{mmol} / \mathrm{L}$ cortisol (H4001, Sigma-Aldrich) and $2.77 \mathrm{mmol} / \mathrm{L}$ cortisone (C2755, Sigma-Aldrich) in methanol. The inter-assay coefficients of variation (CVs) for cortisol were 6 and 7\% at control levels of 1.4 and $50 \mathrm{nmol} / \mathrm{L}$, respectively. The CVs for cortisone were $7 \%$ at both control levels, 4 and $110 \mathrm{nmol} / \mathrm{L}$. The lower limit of quantification (LLoQ) was defined as the lowest concentration where the signal-tonoise ratio was greater than 10:1; accuracy was within $\pm 20 \%$; and imprecision was less than CV $20 \%$ for ten prepared samples. The LLoQs for cortisol and cortisone were $0.25 \mathrm{nmol} / \mathrm{L}$ and $0.20 \mathrm{nmol} / \mathrm{L}$, respectively.

Plasma cortisol levels in reference individuals were analysed consecutively with Roche Elecsys Cortisol I and II reagents on Cobas e602 analyser at Umeå University hospital. The CV was $<6 \%$ at $300 \mathrm{nmol} / \mathrm{L}$ (23). Plasma cortisol levels in patients with CS were analysed with the method in use at the treating hospital. Plasma dexamethasone was analysed with LC-MS/MS at Bergen university hospital, with a lower limit of normal of $3.3 \mathrm{nmol} / \mathrm{L}$ the morning after DST, as described previously (24).

\section{Defining the reference population and reference samples}

Reference intervals were calculated according to the recommendations of the CLSI (19).
Defining the eligible reference samples included two steps of exclusion, in addition to the predefined exclusion criteria. Individual samples with a cortisol:cortisone ratio above the 97.5 th percentile were excluded $(n=10$ of 465 samples), for suspicion of contamination with blood or exogenous hydrocortisone. Then, extreme outliers were excluded from the reference samples, according to the Dixon method; that is, when the difference between the highest value and the second highest value was $>1 / 3$ of the total range of all values, that high value was considered an outlier ( $n=6$ of 455 samples) (19). The same procedure was implemented for samples collected at 20:00 and 22:00 h.

\section{Subgroup comparisons}

Salivary cortisol and cortisone levels at separate time points were compared between subgroups of the reference population (Table 3). Thus, subgroup analyses were conducted by repeatedly dichotomizing the reference population, based on gender (male/female), age (under or $\geq 70$ years), BMI (under or $\geq 30 \mathrm{~kg} / \mathrm{m}^{2}$ ), tobacco use ( $\mathrm{Y} / \mathrm{N}$ to smoking or using snus), self-reported mild oral problems $(\mathrm{Y} / \mathrm{N})$, diabetes $(\mathrm{Y} / \mathrm{N})$, current pharmacological treatment for hypertension $(\mathrm{Y} / \mathrm{N})$, and significant sleep disturbances (ISI score under or $\geq 15$ ).

To evaluate the effect of oestrogen status, we compared several subgroups of women, including premenopausal and postmenopausal female reference subjects; premenopausal use of oestrogen containing OC, hormonal intrauterine device, or no exogenous oestrogens; and postmenopausal use of local oestrogens, or no oestrogens (Table 4). Only one postmenopausal woman used oral hormonal replacement therapy (HRT) and therefore no comparison was made. In two women, menopausal status was not confidently established; therefore, these subjects were excluded from these analyses.

\section{Statistical analysis}

Our data did not follow a Gaussian distribution; therefore, only non-parametric statistics was used. Reference ranges were calculated with the 2.5 th and 97.5 th percentiles, and the $95 \%$ CIs of these percentiles were calculated with the bootstrap method. Subgroups within the reference population were compared with the Mann-Whitney $U$ test, which was also used when comparing cortisol:cortisone ratios between the reference group and the CS group. The Wilcoxon signed-rank test was used when comparing samples collected from the same individual at different time points, including changes in the cortisol:cortisone 
Table 3 Comparison of the salivary cortisol and cortisone values measured at 08:00 h, 23:00 h, and after DST, in different subgroups within the reference population.

\begin{tabular}{|c|c|c|c|c|c|c|c|}
\hline \multirow[b]{2}{*}{ Group } & \multirow[b]{2}{*}{$\boldsymbol{n}$} & \multicolumn{3}{|c|}{$\begin{array}{c}\text { Median salivary cortisol, } \mathrm{nmol} / \mathrm{L} \\
\text { (25th-75th percentile) }\end{array}$} & \multicolumn{3}{|c|}{$\begin{array}{l}\text { Median salivary cortisone, } \mathrm{nmol} / \mathrm{L} \\
\text { (25th-75th percentile) }\end{array}$} \\
\hline & & $08: 00 \mathrm{~h}$ & $23: 00 \mathrm{~h}$ & DST & $08: 00 \mathrm{~h}$ & $23: 00 \mathrm{~h}$ & DST \\
\hline All & 155 & $8.4(5.2-13.0)$ & $0.68(0.40-1.3)$ & $0.17(0.11-0.26)$ & $28.9(22.3-36.7)$ & $4.3(3.0-7.0)$ & $1.3(1.0-1.7)$ \\
\hline Female & 91 & $8.3(5.1-13.2)$ & $0.73(0.40-1.3)$ & $0.19(0.12-0.27)$ & $28.9(22.0-36.4)$ & $4.5(3.2-6.3)$ & $1.3(1.1-1.8)$ \\
\hline Male & 64 & $9.1(5.8-12.8)$ & $0.60(0.35-1.3)$ & $0.15(0.11-0.25)$ & $28.7(22.8-37.6)$ & $3.6(2.9-8.0)$ & $1.2(1.0-1.6)$ \\
\hline \multicolumn{8}{|l|}{ BMI } \\
\hline$\geq 30$ & 20 & $7.6(5.0-10.9)$ & $0.61(0.38-1.3)$ & $0.19(0.15-0.27)$ & $29.8(19.0-37.3)$ & $4.1(2.6-6.0)$ & $1.4(1.0-1.7)$ \\
\hline$<30$ & 135 & $8.7(5.3-13.2)$ & $0.69(0.40-1.3)$ & $0.17(0.11-0.27)$ & $28.5(22.7-36.7)$ & $4.3(3.0-7.0)$ & $1.3(1.0-1.7)$ \\
\hline \multicolumn{8}{|l|}{ Diabetes } \\
\hline Yes & 6 & $9.6(7.9-10.9)$ & $1.7 *(1.0-3.4)$ & $0.26(0.17-0.54)$ & $31.1(25.4-34.4)$ & $8.5(4.7-12.3)$ & $1.6(1.2-2.6)$ \\
\hline No & 149 & $8.3(5.2-13.1)$ & $0.67(0.39-1.1)$ & $0.17(0.11-0.26)$ & $28.7(22.2-37.1)$ & $4.3(3.0-6.7)$ & $1.3(1.0-1.7)$ \\
\hline \multicolumn{8}{|l|}{ Hypertension } \\
\hline Yes & 24 & $8.9(4.9-13.8)$ & $1.2 *(0.54-1.8)$ & $0.21(0.16-0.27)$ & $28.7(22.2-37.6)$ & $5.7(2.9-7.3)$ & $1.4(1.2-1.7)$ \\
\hline No & 131 & $8.3(5.2-13.0)$ & $0.65(0.39-1.1)$ & $0.16(0.11-0.27)$ & $28.7(22.5-36.6)$ & $4.3(3.0-7.0)$ & $1.2(1.0-1.7)$ \\
\hline \multicolumn{8}{|l|}{ Age } \\
\hline$\geq 70$ & 15 & $8.7(5.9-15.0)$ & $1.5 * *(0.85-2.2)$ & $0.25(0.16-0.35)$ & $26.6(22.3-34.1)$ & $6.9 *(5.4-9.7)$ & $1.6 *(1.4-2.5)$ \\
\hline$<70$ & 140 & $8.3(5.2-13.0)$ & $0.65(0.39-1.1)$ & $0.17(0.11-0.25)$ & $29.1(22.2-37.6)$ & $4.0(3.0-6.4)$ & $1.2(1.0-1.7)$ \\
\hline \multicolumn{8}{|l|}{ Tobacco use } \\
\hline Smokers & 7 & $17.0 * *(9.0-23.6)$ & $1.6(0.43-1.7)$ & $0.23(0.09-0.37)$ & $40.1 *(32.2-57.9)$ & $6.3(3.4-10.1)$ & $1.4(1.0-2.0)$ \\
\hline No tobacco & 128 & $8.2(5.2-11.5)$ & $0.66(0.39-1.1)$ & $0.17(0.11-0.27)$ & $27.9(22.1-35.1)$ & $4.3(3.0-6.9)$ & $1.3(1.0-1.7)$ \\
\hline Snus users & 20 & $10.4(5.4-13.5)$ & $0.91(0.40-1.4)$ & $0.18(0.13-0.23)$ & $34.8 *(25.6-42.2)$ & $4.3(2.7-8.1)$ & $1.2(1.0-1.9)$ \\
\hline \multicolumn{8}{|l|}{ ISI score } \\
\hline$\geq 15$ & 7 & $8.4(5.2-12.8)$ & $0.60(0.48-0.68)$ & $0.18(0.10-0.25)$ & $31.6(26.6-39.2)$ & $4.8(3.0-7.9)$ & $1.4(1.0-2.0)$ \\
\hline$<15$ & 148 & $8.4(5.2-13.1)$ & $0.71(0.39-1.3)$ & $0.17(0.11-0.27)$ & $28.6(22.2-36.5)$ & $4.3(3.0-7.0)$ & $1.3(1.0-1.7)$ \\
\hline \multicolumn{8}{|l|}{ Oral problems } \\
\hline Mild & 7 & $8.4(5.8-10.2)$ & $0.67(0.43-0.95)$ & $0.19(0.08-0.26)$ & $22.2(20.0-30.9)$ & $4.8(3.7-5.8)$ & $1.2(1.0-1.4)$ \\
\hline No & 148 & $8.4(5.2-13.1)$ & $0.68(0.39-1.3)$ & $0.17(0.11-0.27)$ & $29.0(22.8-36.9)$ & $4.3(3.0-7.1)$ & $1.3(1.0-1.7)$ \\
\hline
\end{tabular}

Pairs of groups were compared with the Mann-Whitney $U$ test. Smokers and snus (moist smokeless tobacco) users were both compared to individuals that did not use tobacco (no tobacco).

$* P<0.05, * * P<0.01$

$\mathrm{BMI}$, body mass index; ISI, Insomnia Severity Index.

Table 4 Oestrogen effects on salivary cortisol and cortisone, measured at 08:00 h, 23:00 h, and after DST in women in the reference population.

\begin{tabular}{|c|c|c|c|c|c|c|c|}
\hline \multirow[b]{2}{*}{ Subgroup of women } & \multirow[b]{2}{*}{$n$} & \multicolumn{3}{|c|}{$\begin{array}{c}\text { Median salivary cortisol, } \mathrm{nmol} / \mathrm{L} \\
\text { (25th-75th percentile) }\end{array}$} & \multicolumn{3}{|c|}{$\begin{array}{l}\text { Median salivary cortisone, } \mathrm{nmol} / \mathrm{L} \\
\text { (25th-75th percentile) }\end{array}$} \\
\hline & & $08: 00 \mathrm{~h}$ & $23: 00 \mathrm{~h}$ & DST & $08: 00 \mathrm{~h}$ & $23: 00 \mathrm{~h}$ & DST \\
\hline Premenopausal (all) & 59 & $8.3(5.3-13.0)$ & $0.73(0.40-1.2)$ & $0.18(0.11-0.29)$ & $30.0(22.5-36.9)$ & $4.7(3.4-6.4)$ & $1.5(1.1-1.9)$ \\
\hline Postmenopausal (all) & 30 & $7.7(4.8-15.1)$ & $0.72(0.38-1.4)$ & $0.21(0.16-0.28)$ & $27.2(21.2-34.7)$ & $4.0(2.9-6.3)$ & $1.2(1.0-1.6)$ \\
\hline Premenopausal + OC & 5 & $14.0 *(8.3-16.4)$ & $0.95(0.71-4.8)$ & $0.23(0.19-0.49)$ & $34.0(23.0-35.6)$ & $5.6(5.0-12.5)$ & $1.7(1.2-2.3)$ \\
\hline $\begin{array}{l}\text { Premenopausal } \\
\text { no oestrogens }\end{array}$ & 45 & $8.2(4.9-11.7)$ & $0.73(0.39-1.0)$ & $0.15(0.11-0.27)$ & $28.7(21.8-36.8)$ & $4.3(3.2-7.5)$ & $1.5(1.1-1.9)$ \\
\hline Premenopausal + IUD & 9 & $10.2(8.0-14.2)$ & $0.67(0.43-1.4)$ & $0.19(0.12-0.33)$ & $36.3(26.3-39.8)$ & $4.8(3.9-6.2)$ & $1.1(0.88-1.4)$ \\
\hline $\begin{array}{l}\text { Postmenopausal } \\
\text { no oestrogens }\end{array}$ & 20 & $8.2(4.7-16.0)$ & $0.52(0.34-1.5)$ & $0.21(0.16-0.28)$ & $29.1(20.0-36.2)$ & $3.5(2.4-6.3)$ & $1.1(1.0-1.5)$ \\
\hline $\begin{array}{l}\text { Postmenopausal+ } \\
\text { local oestrogens }\end{array}$ & 9 & $8.4(5.8-14.6)$ & $0.85(0.55-1.1)$ & $0.26(0.14-0.45)$ & $29.4(21.1-33.7)$ & $5.4(3.9-7.0)$ & $1.4(1.1-1.6)$ \\
\hline \multicolumn{8}{|c|}{$\begin{array}{l}\text { Pairs of groups that did/did not useoestrogen were compared with the Mann-Whitney } U \text { test. } \\
\star P<<0.05 \text {. }\end{array}$} \\
\hline
\end{tabular}


ratio over time. Seasonal differences (3-month periods) were evaluated with the Kruskal-Wallis non-parametric ANOVA. Sensitivity and specificity tests for correctly identifying patients with CS was performed using the upper reference limit (i.e., the 97.5th percentile for the reference group). Receiver-operating characteristic (ROC) analyses were performed for each test, and the statistical software package, R v 3.5.2 (R Core Team, Vienna, Austria), was used to compare areas under the ROC curves (AUCs) and to calculate the $95 \%$ CIs for sensitivity and specificity with the bootstrap method. LNSC was used as reference standard when comparing test accuracy for novel diagnostic tests, including salivary cortisone at 23:00 h, salivary cortisol and cortisone after DST and combinations of these tests. All other calculations were performed with IBM SPSS Statistics, version 25 (IBM corp.). $P$ values $<0.05$ were considered significant.

\section{Results}

\section{Salivary cortisol:cortisone ratio}

The salivary cortisol:cortisone ratio was calculated from 720 salivary samples, from all time points, both from the reference group $(n=155)$, pregnant women $(n=6)$ and the patients with CS $(n=22)$. For samples with cortisol or cortisone below the LLoQ the ratio was set to 0 . The median cortisol:cortisone ratio was 0.17 and the 97.5th percentile was 1.07. Apart from one sample with a ratio of 1.06, the next closest ratio to the 97.5th percentile value was 0.81 (Fig. 1). Therefore, all saliva samples with cortisol:cortisone ratios $\geq 1.0$ were considered potentially contaminated with blood or exogenous hydrocortisone,

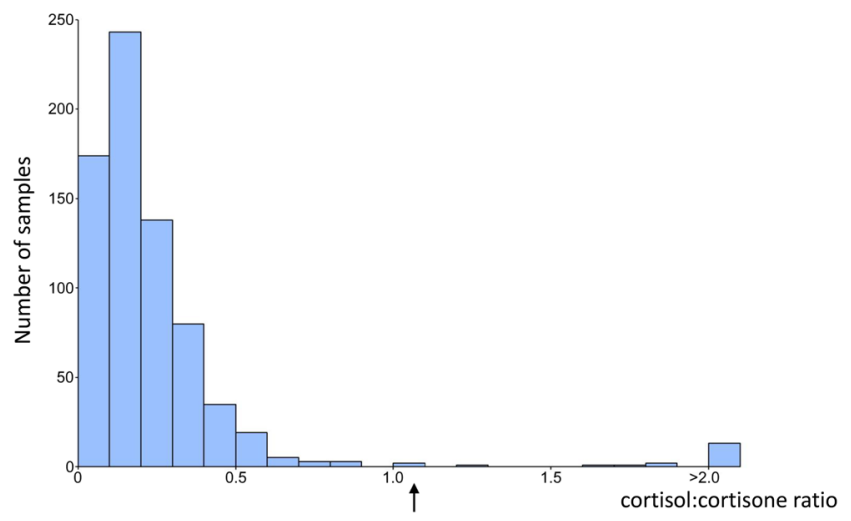

\section{Figure 1}

Distribution of salivary cortisol:cortisone ratios in 720 samples. The arrow indicates the 97.5th percentile. and excluded from further analyses $(n=20$ of 720 samples). Notably, all reference samples excluded due to cortisol:cortisone ratios $\geq 1.0$ had salivary cortisone levels below the 97.5 th percentile at each time point (calculated after exclusion of these samples). Samples collected at 08:00 h, 23:00 h, and after DST had median (25th-75th percentiles) salivary cortisol:cortisone ratios of $0.29(0.23$ $0.36), 0.14(0.11-0.21)$, and $0.12(0.09-0.17)$, respectively. The salivary cortisol:cortisone ratio was significantly higher at 08:00 $\mathrm{h}$ than at 23:00 $\mathrm{h}$ and after DST $(P<0.001$ for both). The salivary cortisol:cortisone ratios were significantly higher in the Cushing population than in the reference population for samples taken at 23:00 $\mathrm{h}(0.28 \mathrm{vs}$ 0.14 ) and after DST ( 0.28 vs $0.12 ; P<0.001$ for both), but not for the unsuppressed samples taken at 08:00 h $(0.32$ vs 0.29 ).

\section{Reference intervals}

For the eligible reference group $(n=155)$, the reference intervals $(2.5$ th -97.5 th percentile) for salivary cortisol were $2.7-22.9 \mathrm{nmol} / \mathrm{L}$ at $08: 00 \mathrm{~h},<0.25-3.6 \mathrm{nmol} / \mathrm{L}$ at 23:00, and <0.25-0.79 nmol/L after DST (Fig. 2). The reference intervals calculated for salivary cortisone were $14.4-57.5 \mathrm{nmol} / \mathrm{L}$ at $08: 00 \mathrm{~h}, 1.5-13.5 \mathrm{nmol} / \mathrm{L}$ at $23: 00 \mathrm{~h}$, and $0.59-3.5 \mathrm{nmol} / \mathrm{L}$ after DST (Fig. 2).

After DST the reference interval for plasma cortisol was $11-134 \mathrm{nmol} / \mathrm{L}$ (median $25 \mathrm{nmol} / \mathrm{L}$ ), calculated from 164 reference subjects, excluding only those that did not complete the DST (pregnant women and subjects with missing blood samples, $n=11$ ).

\section{Discriminating patients with Cushing's syndrome from the reference population}

Patients with CS had considerably higher salivary cortisol and cortisone levels at 23:00 $\mathrm{h}$ and after DST, compared to the reference population (Fig. 3). The sensitivity and specificity of the index tests, that is salivary cortisol and cortisone at 23:00 $\mathrm{h}$ and after DST, to identify patients with CS was tested using the upper limits of the reference intervals as cut-off values (Table 5). To mimic the clinical diagnostic situation as closely as possible in these analyses, only samples with cortisol:cortisone ratios $\geq 1.0$, were excluded, whereas reference individuals using local, inhaled, or nasal glucocorticoids and extreme outliers were included $(n=164)$.

We found that salivary cortisol and cortisone could discriminate CS from the reference population with high sensitivity and specificity (Fig. 3 and Table 5). Notably, the 

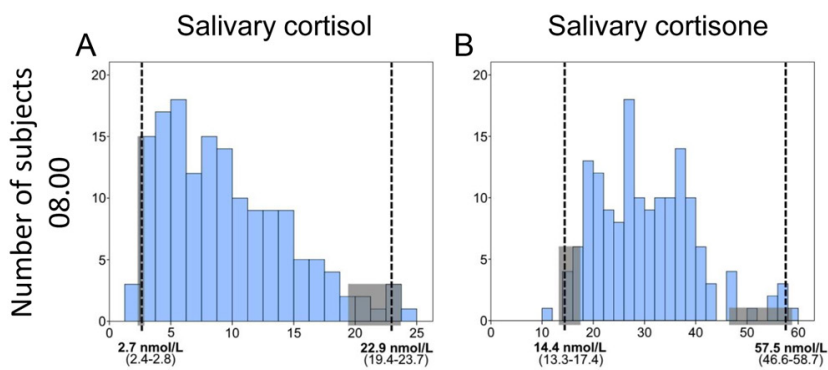

C

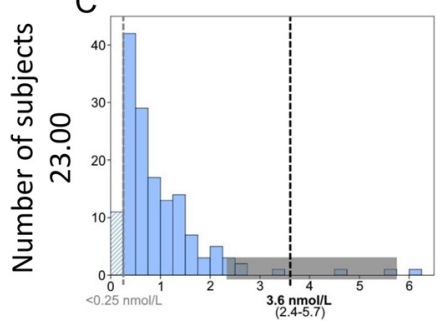

$\mathrm{E}$

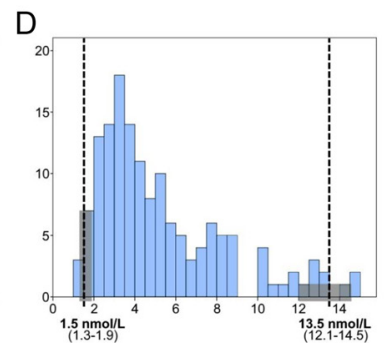

$\mathrm{F}$
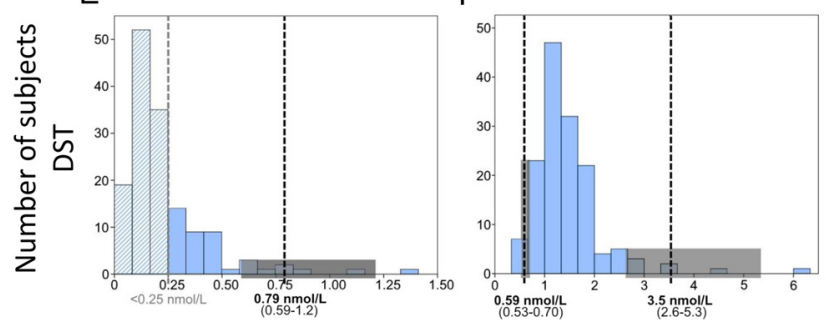

Figure 2

Reference intervals for salivary cortisol ( $A, C$ and $E$ ) and salivary cortisone ( $B, D$ and $F$ ), measured at three different time points. All values on the $\mathrm{X}$-axes are expressed in $\mathrm{nmol} / \mathrm{L}$. Dashed lines mark the 2.5th and 97.5th percentile boundaries of each interval. Grey shaded boxes and the values below indicate the mean value $(95 \% \mathrm{Cl})$ at each boundary. For salivary cortisol at 23:00 $\mathrm{h}$ and after DST, the 2.5th percentile was below the lower limit of quantification for the LC-MS/ MS-method ( $<0.25 \mathrm{nmol} / \mathrm{L})$. DST, overnight dexamethasone suppression test.

ROC curve AUC for salivary cortisone at 23:00 h (AUC: 0.985) was significantly higher than that of LNSC (salivary cortisol at 23:00 h) (AUC: 0.976; $P=0.029$ ) (Supplementary Fig. 1, see section on supplementary materials given at the end of this article). The diagnostic accuracies (ROC curve AUCs) of the salivary cortisol and cortisone levels measured after the DST were not significantly different from the diagnostic accuracy of LNSC or the conventional DST with plasma cortisol.

To evaluate novel approaches in CS diagnostics based on salivary glucocorticoids, we also tested the diagnostic accuracy of the sum of salivary cortisol and cortisone levels (i.e. $\Sigma$ ), measured either at 23:00 h or after the DST.
The former showed significantly better diagnostic value than the LNSC $(P=0.049)$, but neither showed better diagnostic value than late-night salivary cortisone alone. We also evaluated whether a combination of salivary cortisol at 23:00 $\mathrm{h}$ and the salivary cortisol after DST (i.e. 23:00+ DST) might increase the diagnostic accuracy. This combined test also showed superior diagnostic accuracy over LNSC, but not over the late-night salivary cortisone. These results were similar, whether we used the absolute salivary cortisol values or the z-scores for each time point. The same results were found for the combination of salivary cortisone measurements at 23:00 h and after DST (Table 5).

\section{Plasma dexamethasone and reference subjects with discrepant results}

Plasma dexamethasone concentrations were measured in 153 reference individuals in the morning of the DST. A previous study using this method indicated that plasma dexamethasone concentrations $\geq 3.3 \mathrm{nmol} / \mathrm{L}$ were sufficient to suppress plasma cortisol below $50 \mathrm{nmol} / \mathrm{L}$ (25). Of the 140 reference individuals with plasma dexamethasone $\geq 3.3 \mathrm{nmol} / \mathrm{L}$, nine $(6.4 \%)$ had plasma cortisol 50-137 nmol/L. Of the 13 subjects with plasma dexamethasone $<3.3 \mathrm{nmol} / \mathrm{L}$, four (31\%) had plasma cortisol $>50 \mathrm{nmol} / \mathrm{L}$. Three reference subjects had plasma cortisol $\geq 138 \mathrm{nmol} / \mathrm{L}$ after the DST; these were excluded from the eligible reference population. All three lacked any clinical manifestations of hypercortisolism, and CS was excluded after repeated follow-up and biochemical tests. Of these three subjects, two had plasma dexamethasone concentrations $<3.3 \mathrm{nmol} / \mathrm{L}$. Notably, all these three subjects had late-night salivary cortisol and cortisone levels within the reference intervals (established after excluding these individuals).

\section{Subgroups in the reference population}

Comparisons of salivary cortisol and cortisone levels between different subgroups within the reference population are presented in Tables 3 and 4. Salivary cortisol at 23:00 h was slightly, but significantly elevated in individuals with hypertension, with diabetes, and age $\geq 70$ years. Reference subjects $\geq 70$ years of age also had significantly elevated salivary cortisone at 23:00 $\mathrm{h}$ and after the DST. Plasma cortisol after DST was also significantly higher in the reference subjects $\geq 70$ years, median (interquartile range (IQR)): $31(27-52) \mathrm{nmol} / \mathrm{L}$ vs subjects $<70$, median: $24(18-31) \mathrm{nmol} / \mathrm{L}(P=0.005)$. Smokers had 

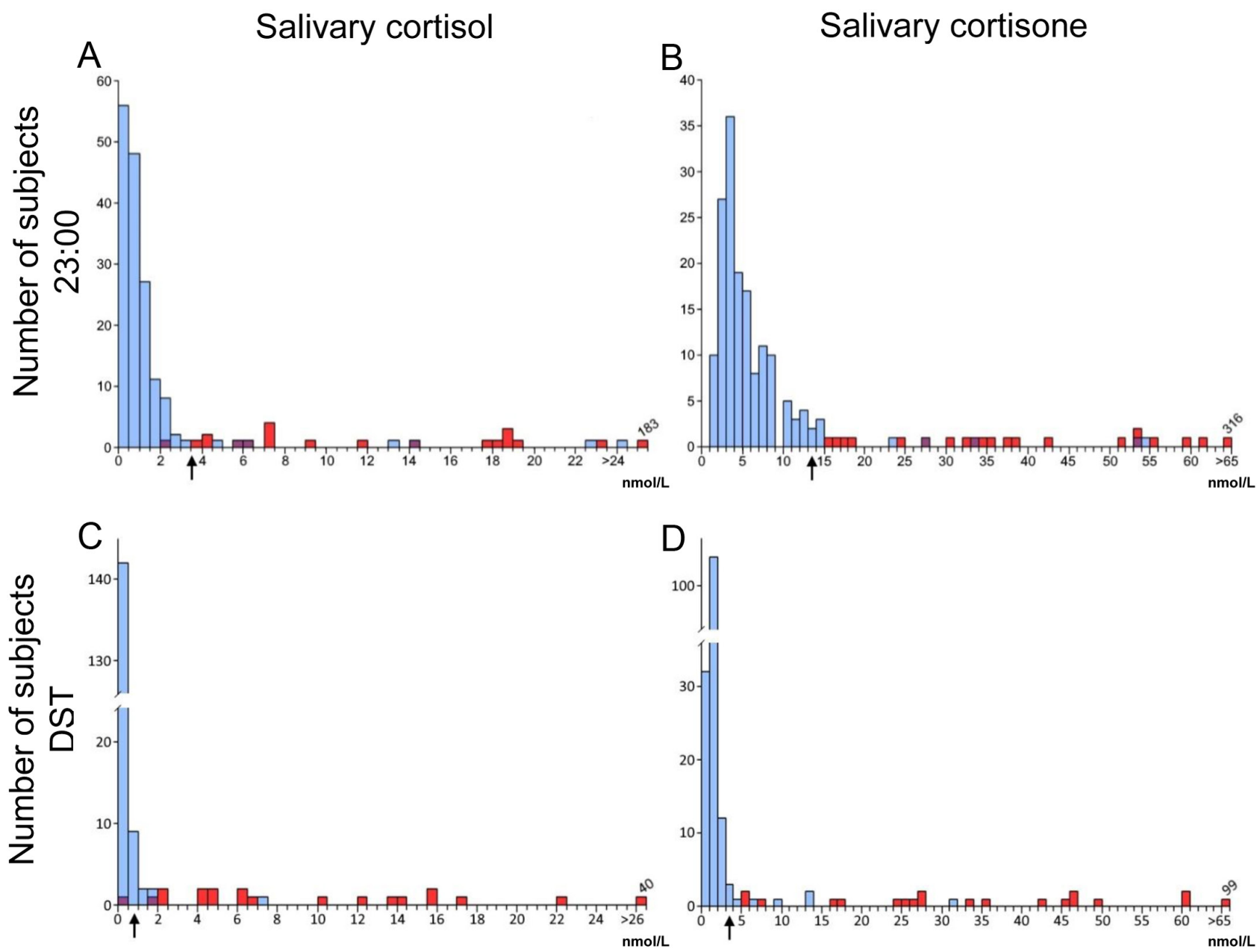

\section{Figure 3}

Comparison of salivary cortisol ( $A$ and $C$ ) and cortisone (B and D) levels, measured at 23:00 h ( $A$ and $B$ ) and after DST (C and D) in the reference population (blue) and patients with CS (red). Arrows indicate the 97.5th percentile value of the reference population, evaluated at each time point. DST, overnight dexamethasone suppression test.

significantly elevated salivary cortisol and cortisone levels in the morning at 08:00, and subjects that used snus had significantly elevated salivary cortisol at 08:00 h. Smokers also had a significantly higher cortisol:cortisone ratio (median: 0.41) at 08:00 h, compared to subjects that did not use tobacco (median: $0.28, P=0.035$ ).

There were no significant differences in salivary cortisol or cortisone between postmenopausal and premenopausal women. Premenopausal women that used oestrogen containing OC $(n=5)$ had significantly higher plasma cortisol levels after DST, median (IQR): 50 (39-77) nmol/L, than premenopausal women without exogenousoestrogen ( $n=45)$; median (IQR): 26 (20-35) $\mathrm{nmol} / \mathrm{L}(P=0.007)$. Premenopausal women using OC also had higher median salivary cortisol and cortisone levels than premenopausal women that did not use exogenous oestrogen, but the difference was only significant for morning (08:00 h) cortisol levels $(P=0.045$; Table 4). Among the postmenopausal women $(n=30)$, use of local oestrogens had no effect upon salivary cortisol or cortisone levels (Table 4), nor did it have effect on plasma cortisol levels after DST $(P=0.281)$. In the pregnant women $(n=6)$, median (IQR) salivary cortisol at 23:00 h was $1.4(0.64$ 2.4) $\mathrm{nmol} / \mathrm{L}$ and cortisone was $5.7 \mathrm{nmol} / \mathrm{L}$ (4.4-13.2). This was not significantly different from the non-pregnant premenopausal women. However, two of the pregnant women had slightly elevated late-night salivary cortisone (15.3 and $18.3 \mathrm{nmol} / \mathrm{L}$ ) based on the upper limit of normal calculated from men and non-pregnant women. DST was not performed in the pregnant women. 
Table 5 Diagnostic test accuracy for identifying CS with salivary cortisol and/or cortisone.

\begin{tabular}{|c|c|c|c|c|c|}
\hline Diagnostic test & $\begin{array}{c}97.5 \text { percentile } \\
(\mathrm{nmol} / \mathrm{L})\end{array}$ & $\begin{array}{l}\text { Sensitivity, \% } \\
(95 \% \mathrm{Cl})\end{array}$ & $\begin{array}{l}\text { Specificity, \% } \\
(95 \% \mathrm{Cl})\end{array}$ & $\begin{array}{c}\text { ROC-curve AUC } \\
(95 \% \mathrm{Cl})\end{array}$ & $\begin{array}{c}\text { P value for } \\
\text { ROC-curve vs LNSC }\end{array}$ \\
\hline \multicolumn{6}{|l|}{$23: 00 \mathrm{~h}$} \\
\hline LNSC & 3.6 & $90(70-99)$ & $96(91-98)$ & $0.976(0.955-0.996)$ & - \\
\hline Salivary cortisone & 13.5 & $100(84-100)$ & 95 (90-98) & 0.985 (0.970-1.000) & 0.038 \\
\hline$\Sigma$ & 16.4 & $100(84-100)$ & 95 (90-98) & $0.983(0.966-1.000)$ & 0.049 \\
\hline \multicolumn{6}{|l|}{ DST } \\
\hline Salivary cortisol & 0.79 & $95(75-100)$ & $96(92-99)$ & $0.988(0.971-1.000)$ & 0.315 \\
\hline Salivary cortisone & 3.5 & $100(83-100)$ & $94(89-97)$ & $0.993(0.985-1.000)$ & 0.097 \\
\hline$\sum$ & 3.9 & $100(83-100)$ & $95(90-98)$ & $0.993(0.985-1.000)$ & 0.109 \\
\hline P-cortisol & 134 & 95 (75-100) & $98(94-100)$ & $0.997(0.992-1.000)$ & 0.050 \\
\hline \multicolumn{6}{|l|}{$23: 00+$ DST $^{*}$} \\
\hline Salivary cortisol & & & & 0.985 (0.970-1.000) & 0.041 \\
\hline Salivary cortisone & & & & $0.993(0.985-1.000)$ & 0.023 \\
\hline
\end{tabular}

\section{Seasonal effects}

Comparing salivary cortisol and cortisone levels at 08:00 $\mathrm{h}, 23: 00 \mathrm{~h}$, and after DST in samples collected during winter (Dec-Feb), spring (Mar-May), summer (Jun-Aug), and autumn (Sep-Nov) showed no significant effects of season (Table 6).

\section{Effect of evening time point}

Finally, we evaluated the effects of different evening sampling time points. Half of the reference population $(n=78)$ collected saliva samples at 20:00 h, 22:00 $\mathrm{h}$ and 23:00 h. Within this group salivary cortisol and cortisone levels were both significantly higher in samples collected at 20:00 h compared to those collected at 23:00 h (median cortisol 0.72 vs $0.60 \mathrm{nmol} / \mathrm{L} ; P=0.014$; cortisone 5.70 vs $3.53 \mathrm{nmol} / \mathrm{L} ; P<0.001)$. No significant difference was found between samples collected at 22:00 $\mathrm{h}$ and those collected at 23:00 h (median cortisol: 0.56 vs 0.60 $\mathrm{nmol} / \mathrm{L} ; P=0.087$; median cortisone: 3.76 vs $3.53 \mathrm{nmol} / \mathrm{L}$; $P=0.603$; Fig. 4). The median reported 'normal bedtime' for this part of the reference population was 23:00 $\mathrm{h}$ (IQR 22:37-23:30 h), only two normally going to bed before 22:00 $\mathrm{h}$ and none before 21:00 $\mathrm{h}$.

\section{Discussion}

Improving the procedure for diagnosing CS requires simple biochemical screening tests with high diagnostic accuracy. The 24-h UFC require strenuous sampling collection for the patient; are often incomplete 24-h collections; have low sensitivity for detecting mild CS; and is difficult to evaluate in patients with moderate renal impairment $(26,27)$. The classic DST with plasma cortisol often yields false high or grey-zone values, due to, for example, variations in plasma CBG concentrations and dexamethasone metabolism. The LNSC benefits from easy sample collection and high accuracy. The test however is hampered by the lack of solid reference intervals and the putative risk of a false high salivary cortisol, caused by sample contamination or the variable conversion of cortisol to cortisone in the salivary gland.

Table 6 Seasonal differences in salivary cortisol and cortisone levels, measured at 08:00 h, 23:00 h, and after DST during each season.

\begin{tabular}{|c|c|c|c|c|}
\hline \multirow[b]{2}{*}{ Season } & \multirow[b]{2}{*}{$n$} & \multicolumn{3}{|c|}{$\begin{array}{l}\text { Median salivary cortisol, } \mathrm{nmol} / \mathrm{L} \\
\text { (25th-75th percentile) }\end{array}$} \\
\hline & & $08: 00 \mathrm{~h}$ & $23: 00 \mathrm{~h}$ & DST \\
\hline Winter (Dec-Feb) & 30 & $7.9(4.8-15.2)$ & $0.70(0.42-1.3)$ & $0.21(0.10-0.37)$ \\
\hline Spring (Mar-May) & 51 & $8.8(5.8-12.8)$ & $0.56(0.40-1.1)$ & $0.16(0.12-0.22)$ \\
\hline Summer (Jun-Aug) & 35 & $9.5(5.9-14.6)$ & $0.85(0.33-1.4)$ & $0.16(0.10-0.26)$ \\
\hline Autumn (Sep-Nov) & 39 & $8.2(4.8-11.5)$ & $0.68(0.40-1.3)$ & $0.20(0.13-0.31)$ \\
\hline
\end{tabular}

\begin{tabular}{|c|c|c|}
\hline \multicolumn{3}{|c|}{$\begin{array}{c}\text { Median salivary cortisone, } \mathrm{nmol} / \mathrm{L} \\
\text { (25th-75th percentile) }\end{array}$} \\
\hline $08: 00 \mathrm{~h}$ & $23: 00 \mathrm{~h}$ & DST \\
\hline $29.4(21.4-37.9)$ & $3.6(3.1-6.0)$ & $1.2(0.87-1.5)$ \\
\hline 31.7 (25.5-39.2) & $4.4(3.0-7.7)$ & $1.4(1.1-1.7)$ \\
\hline $29.8(23.4-37.1)$ & $5.1(2.6-8.2)$ & $1.2(0.91-1.8)$ \\
\hline $26.1(20.9-34.5)$ & $4.4(3.2-6.4)$ & $1.4(1.0-1.9)$ \\
\hline
\end{tabular}

No significant difference was found among the different seasons (Kruskal-Wallis ANOVA). 

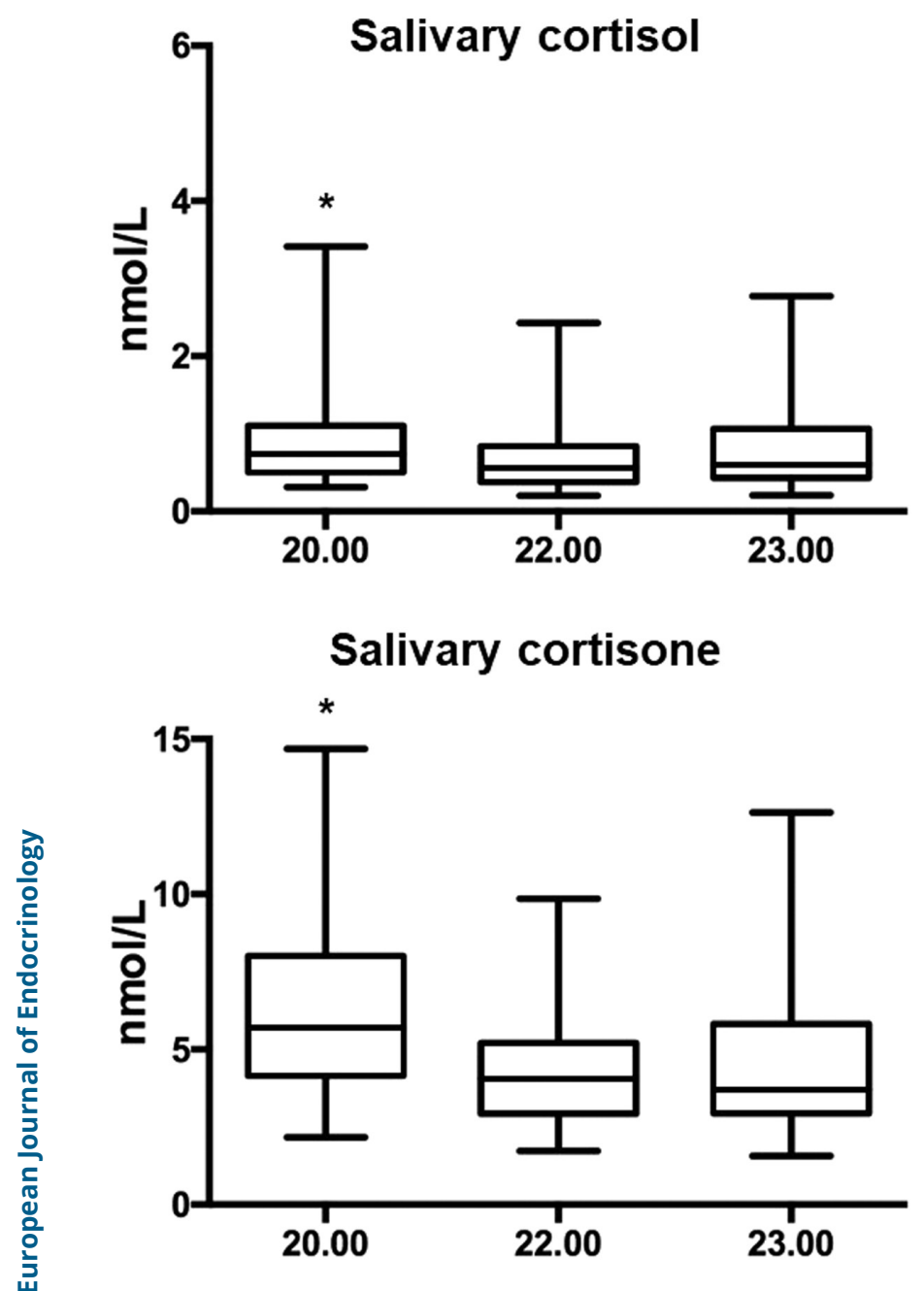

Figure 4

Effects of different evening sampling time points on salivary cortisol and cortisone levels. Boxes represent the 25th-75th percentiles and whiskers are the 2.5th and 97.5th percentiles, ${ }^{*} P<0.05$ with the Wilcoxon signed-rank test.

In this study, we established robust reference intervals for salivary cortisol and salivary cortisone at 23:00 h and after DST, measured with LC-MS/MS. By comparing patients with CS with the reference population we showed that both the established biomarker for CS, LNSC, and the less established biomarkers/tests, that is salivary cortisone at 23:00 $\mathrm{h}$ and salivary cortisol and cortisone after DST all have very high sensitivity and specificity for identifying patients with CS using the newly established upper reference limits. The accuracy of salivary cortisone at 23:00 was significantly higher than that of cortisol; this result suggests that salivary cortisone should be the primary measurand.
Steroid quantification with LC-MS/MS is increasingly common, due to advantages including high specificity and the ability to analyse similar steroids simultaneously. Our simultaneous quantifications of salivary cortisol and cortisone revealed a median salivary cortisol:cortisone ratio of 0.18 and a 97.5 th percentile of 1.07 . These findings supported the exclusion of samples with cortisol:cortisone ratios above 1 , due to potential sample contamination or variation in 11 $\beta$-HSD2 activity in the salivary gland (e.g., intrinsic enzyme variations or inhibition by glycyrrhizic acid or grapefruit juice) $(28,29,30,31,32)$. Elevated saliva cortisol:cortisone ratio is very useful to detect sample contamination with topical hydrocortisone but is also increased by blood contamination of the saliva sample (i.e. by rifts in the oral mucosa). The latter may however also be addressed by other methods, including discoloration ratings or measurements of hemoglobin or transferrin in the saliva sample (33). Consistent with other studies, we found a higher salivary cortisol:cortisone ratio in samples with higher plasma cortisol levels (i.e. samples taken at 08:00 $\mathrm{h}$ and from patients with CS), indicating that the salivary gland $11 \beta$-HSD2 was saturated $(6,9,34)$.

Our stringently acquired reference intervals for latenight salivary cortisol and cortisone levels, measured with LC-MS/MS, were comparable to those previously reported $(8,35,36)$. While both late-night salivary cortisol and cortisone showed high diagnostic accuracy for identifying patients with CS we found late-night salivary cortisone to be slightly, but significantly better than late-night salivary cortisol, consistent with previous studies $(3,8,15$, $25,35)$. We also explored the use of saliva samples after the DST, after establishing reference intervals for salivary cortisol and cortisone. Also after DST we found high diagnostic accuracy of salivary cortisol and cortisone, and both were noninferior to the conventional DST with plasma cortisol. Furthermore, it should be noted that all reference subjects that were excluded due to high salivary cortisol:cortisone ratios $(\geq 1.0)$ had salivary cortisone values within the calculated reference intervals. Taken together, these findings indicate that analysing salivary cortisone for CS screening and diagnosis might provide higher stability and a lower risk of false results (e.g. due to sample contamination or low $11 \beta-H S D 2$ activity in the salivary gland), compared to salivary cortisol, as suggested previously $(16,35)$.

We also evaluated the diagnostic accuracy of different combined tests. The sum of salivary cortisol and salivary cortisone at 23:00 h (or after DST) could potentially better reflect the free plasma cortisol level at each time point. 
Alternatively, the sum of salivary cortisol (or cortisone) levels measured at 23:00 and after the DST that evaluates both the evening nadir and the suppressibility in one test might be superior to one individual sample. In this study we found that both of these combined tests had significantly higher diagnostic accuracy than the traditional LNSC alone, but not higher accuracy than the salivary cortisone at 23:00 h alone. However, we cannot exclude that a simple sequential evaluation of salivary glucocorticoids, measured both at the diurnal nadir and after DST could potentially increase the accuracy of diagnosing CS, and thus, it merits further study (27).

The traditional sampling time for LNSC at 23:0000:00 $\mathrm{h}$ might be rather late for some individuals; thus, it could potentially induce stress and raise cortisol levels. A recent study found salivary cortisol and cortisone levels well below the upper limit of normal in healthy subjects sampled at their normal bedtime (36). In the current study, we found no significant difference in salivary cortisol or cortisone collected at 22:00 vs 23:00 h, whereas samples collected at 20:00 h had significantly higher levels. This suggests that unstressed late-night salivary sampling for cortisol and cortisone may be collected at $22.00 \mathrm{~h}$ or later but that sampling at 20:00 $\mathrm{h}$ is not representative as latenight samples using these reference intervals.

It has been suggested that, in addition to the wellknown diurnal variation, cortisol levels might also have a seasonal variation $(37,38,39,40,41,42)$. We collected reference samples over a one-year period in Umeå (northern Sweden), which experiences approximately 21 $\mathrm{h}$ of daylight in June and $4 \mathrm{~h}$ in December, in addition to considerable seasonal temperature variations. Despite substantial variations in these factors suggested to seasonally affect cortisol secretion, we observed no significant seasonal differences in salivary cortisol or cortisone levels, measured at either at 23:00 h or after DST. This finding indicates that the reference intervals can remain constant throughout the year, when evaluating hypercortisolaemic states.

Previous studies have shown that cortisol levels increase with aging, overweight, tobacco use, exogenousoestrogen use, sleep disturbances, and common diseases. Thus, the diagnosis of CS is more difficult in those groups $(12,17,38,39,43,44,45,46,47,48$, 49). Within the current reference group, we found significantly elevated salivary cortisol levels at 23:00 in subjects with hypertension and diabetes. Furthermore, reference subjects over 70 years had significantly higher salivary cortisol and cortisone levels at 23:00 $\mathrm{h}$ and salivary cortisone after DST, in line with previously shown higher LNSC in older vs younger healthy subjects (49). Accordingly, when interpreting salivary cortisol and cortisone levels in these subgroups, slightly higher values may be expected, depending on the sampling time point. Nonetheless, it should be noted that patients with CS could be differentiated from reference subjects with high sensitivity and specificity, based on the 97.5th percentile value for the entire reference population, including all of these subgroups. Based on the current study findings, we therefore do not recommend separate reference ranges for the subgroups investigated. However, as the number of subjects with different BMI, tobacco habits and different common diseases are very few, the secondary analyses regarding salivary cortisol and cortisone in subgroups of the reference population are considered exploratory and larger studies are needed to specifically address the impact of these factors upon salivary cortisol and cortisone. Furthermore, we did not actively recruit or reject individuals with non-CS hypercortisolaemic states, including depression, alcohol abuse, and severe obesity (i.e. pseudo-Cushing syndromes). Further studies are needed to establish whether separate reference intervals and cut-off values for salivary cortisol and cortisone are needed for these important groups of patients. We found no significant effects of tobacco use in samples collected at 23:00 h or after DST, but spontaneous 08:00 h salivary cortisol and cortisone levels and the cortisol:cortisone ratio were elevated in smokers. These increased morning levels in smokers might be due to the sampling instructions, which did not allow smoking for one hour prior to sampling, which could have potentially caused abstinence-related stress. Moreover, the increased ratio could be due to either 11 $\beta-\mathrm{HSD} 2$ enzyme saturation or inhibition, because tobacco sometimes contains glycyrrhizic acid $(6,9)$.

Oestrogen is known to increase circulating CBG levels, with concomitant increases in total plasma cortisol. This could cause difficulties in interpreting diagnostic tests for HPA-axis abnormalities in women that are pregnant or using OC $(3,16,18,50)$. Because saliva samples represent the free fraction of cortisol, salivary measurements should be unaffected by OC and pregnancy. However, some studies have shown elevations in both LNSC and free plasma cortisol levels with estrogen loads - albeit with methodological variations $(4,16,18,50,51,52,53)$. In this study, the five premenopausal women taking OC had significantly higher plasma cortisol after DST than nonOC-using premenopausal women. There was also a trend for higher salivary cortisol and cortisone in women with higher estrogen load, i.e. OC users and pregnant women. 
However, this was not significant and warrants further studies.

A strength of our study was the prospectively collected large reference cohort that well represent the general adult population. We also evaluated the different tests in a reasonably large, representative group of patients, spanning from mild to severe CS. The study limitations included the small subgroups within the reference population, and the overlap between subgroups (e.g. reference subjects with hypertension might also be over 70 years of age and have diabetes). Establishing clinically relevant reference intervals includes a careful choice of relevant reference subjects and exclusion of subjects and samples not considered representative. The current study was made in accordance with the CLSI guidelines for defining, establishing, and verifying reference intervals in the clinical laboratory and all outliers were carefully assessed before exclusion (19). Future studies are needed to validate the observed sensitivity and specificity of salivary cortisol and cortisone for detecting CS. These markers should also be tested in other relevant groups, including patients with adrenal incidentalomas.

In conclusion, we have established robust reference values for salivary cortisol and salivary cortisone, measured at 23:00 $\mathrm{h}$ and after DST with LC-MS/MS. No differences were found between samples collected at 22:00 and 23:00 $\mathrm{h}$ indicating that LNSC may be collected from 22:00 h. Salivary cortisol and cortisone at 23:00 h and after DST had a high diagnostic accuracy for CS, with salivary cortisone showing a slightly, but significantly higher diagnostic accuracy than salivary cortisol, in conjunction with favourable robustness to putative preanalytical errors.

\section{Supplementary materials}

This is linked to the online version of the paper at https://doi.org/10.1530/ EJE-19-0872.

\section{Declaration of interest}

The authors declare that there is no conflict of interest that could be perceived as prejudicing the impartiality of this study.

\section{Funding}

This study was supported by a donation to Umeå University for research on pituitary disease.

\section{Acknowledgements}

Many thanks to Katarina Iselid at Clinical Research Centre, Umeå University Hospital, for the skilful inclusion of reference individuals and for handling samples. The authors also thank Anders Lundquist and Marie Eriksson for statistical advice. Additionally, they thank Ersilia Bifulco and Steinar Hustad, at the Core Facility for Metabolomics, University of Bergen, for the analysis of plasma dexamethasone.

\section{References}

1 Nieman LK. Cushing's syndrome: update on signs, symptoms and biochemical screening. European Journal of Endocrinology 2015173 M33-M38. (https://doi.org/10.1530/EJE-15-0464)

2 Vining RF, McGinley RA, Maksvytis JJ \& Ho KY. Salivary cortisol: a better measure of adrenal cortical function than serum cortisol. Annals of Clinical Biochemistry 198320 329-335. (https://doi. org/10.1177/000456328302000601)

3 Perogamvros I, Keevil BG, Ray DW \& Trainer PJ. Salivary cortisone is a potential biomarker for serum free cortisol. Journal of Clinical Endocrinology and Metabolism 201095 4951-4958. (https://doi. org/10.1210/jc.2010-1215)

4 Meulenberg PM, Ross HA, Swinkels LM \& Benraad TJ. The effect of oral contraceptives on plasma-free and salivary cortisol and cortisone. Clinica Chimica Acta: International Journal of Clinical Chemistry 1987165 379-385. (https://doi.org/10.1016/00098981(87)90183-5)

5 Smith RE, Maguire JA, Stein-Oakley AN, Sasano H, Takahashi K, Fukushima K \& Krozowski ZS. Localization of 11 beta-hydroxysteroid dehydrogenase type II in human epithelial tissues. Journal of Clinical Endocrinology and Metabolism 199681 3244-3248. (https://doi. org/10.1210/jcem.81.9.8784076)

6 Bocchi B, Fagart J, Cluzeaud F, Fay M, Rafestin-Oblin ME \& Farman N. Glucocorticoid metabolism by 11-beta hydroxysteroid dehydrogenase type 2 modulates human mineralocorticoid receptor transactivation activity. Journal of Steroid Biochemistry and Molecular Biology 200384 239-244. (https://doi.org/10.1016/s09600760(03)00036-0)

7 Dunn JF, Nisula BC \& Rodbard D. Transport of steroid hormones: binding of 21 endogenous steroids to both testosterone-binding globulin and corticosteroid-binding globulin in human plasma. Journal of Clinical Endocrinology and Metabolism 198153 58-68. (https://doi.org/10.1210/jcem-53-1-58)

8 Antonelli G, Ceccato F, Artusi C, Marinova M \& Plebani M. Salivary cortisol and cortisone by LC-MS/MS: validation, reference intervals and diagnostic accuracy in Cushing's syndrome. Clinica Chimica Acta: International Journal of Clinical Chemistry 2015451 247-251. (https://doi.org/10.1016/j.cca.2015.10.004)

9 Perogamvros I, Owen LJ, Newell-Price J, Ray DW, Trainer PJ \& Keevil BG. Simultaneous measurement of cortisol and cortisone in human saliva using liquid chromatography-tandem mass spectrometry: application in basal and stimulated conditions. Journal of Chromatography: B, Analytical Technologies in the Biomedical and Life Sciences 2009877 3771-3775. (https://doi.org/10.1016/j. jchromb.2009.09.014)

10. Ray JA, Kushnir MM, Rockwood AL \& Meikle AW. Analysis of cortisol, cortisone and dexamethasone in human serum using liquid chromatography tandem mass spectrometry and assessment of cortisol: cortisone ratios in patients with impaired kidney function. Clinica Chimica Acta: International Journal of Clinical Chemistry 2011 412 1221-1228. (https://doi.org/10.1016/j.cca.2011.03.016)

11 Homma M, Tanaka A, Hino K, Takamura H, Hirano T, Oka K, Kanazawa M, Miwa T, Notoya Y, Niitsuma T et al. Assessing systemic 11beta-hydroxysteroid dehydrogenase with serum cortisone/cortisol ratios in healthy subjects and patients with diabetes mellitus and chronic renal failure. Metabolism: Clinical and Experimental 200150 801-804. (https://doi.org/10.1053/meta.2001.24213)

12 Blair J, Adaway J, Keevil B \& Ross R. Salivary cortisol and cortisone in the clinical setting. Current Opinion in Endocrinology, 
Diabetes, and Obesity 201724 161-168. (https://doi.org/10.1097/ MED.0000000000000328)

13 Raff H \& Singh RJ. Measurement of late-night salivary cortisol and cortisone by LC-MS/MS to assess preanalytical sample contamination with topical hydrocortisone. Clinical Chemistry 201258 947-948. (https://doi.org/10.1373/clinchem.2012.182717)

14 Lee S, Lim HS, Shin HJ, Kim SA, Park J, Kim HC, Kim H, Kim HJ, Kim YT, Lee KR et al. Simultaneous determination of cortisol and cortisone from human serum by liquid chromatography-tandem mass spectrometry. Journal of Analytical Methods in Chemistry 2014 2014 787483. (https://doi.org/10.1155/2014/787483)

15 Debono M, Harrison RF, Whitaker MJ, Eckland D, Arlt W, Keevil BG $\&$ Ross RJ. Salivary cortisone reflects cortisol exposure under physiological conditions and after hydrocortisone. Journal of Clinical Endocrinology and Metabolism 2016101 1469-1477. (https://doi. org/10.1210/jc.2015-3694)

16 Perogamvros I, Aarons L, Miller AG, Trainer PJ \& Ray DW. Corticosteroid-binding globulin regulates cortisol pharmacokinetics. Clinical Endocrinology 201174 30-36. (https://doi.org/10.1111/ j.1365-2265.2010.03897.x)

17 Carroll T, Raff H \& Findling JW. Late-night salivary cortisol measurement in the diagnosis of Cushing's syndrome. Nature Clinical Practice: Endocrinology and Metabolism 20084 344-350. (https://doi. org/10.1038/ncpendmet0837)

18 Gatti R, Antonelli G, Prearo M, Spinella P, Cappellin E \& De Palo EF. Cortisol assays and diagnostic laboratory procedures in human biological fluids. Clinical Biochemistry 200942 1205-1217. (https:// doi.org/10.1016/j.clinbiochem.2009.04.011)

19 Horowitz GL, Altaie S, Boyd JC, Ceriotti F, Garg U, Horn P, Pesce A, Sine HE \& Zakowski J. Defining, Establishing, and Verifying Reference Intervals in the Clinical Laboratory; Approved Guideline - Third Edition, C28-A3 ed. Clinical and Laboratory Standards Institute, 2010.

20 Bastien CH, Vallieres A \& Morin CM. Validation of the Insomnia Severity Index as an outcome measure for insomnia research. Sleep Medicine 20012 297-307. (https://doi.org/10.1016/s13899457(00)00065-4)

21 Fassnacht M, Arlt W, Bancos I, Dralle H, Newell-Price J, Sahdev A, Tabarin A, Terzolo M, Tsagarakis S \& Dekkers OM. Management of adrenal incidentalomas: European Society of Endocrinology Clinical Practice Guideline in collaboration with the European Network for the Study of Adrenal Tumors. European Journal of Endocrinology 2016 175 G1-G34. (https://doi.org/10.1530/EJE-16-0467)

22 Israelsson M, Brattsand R \& Brattsand G. 20alpha- and 20betaDihydrocortisone may interfere in LC-MS/MS determination of cortisol in saliva and urine. Annals of Clinical Biochemistry $2018 \mathbf{5 5}$ 341-347. (https://doi.org/10.1177/0004563217724178)

23 Vogeser M, Kratzsch J, Ju Bae Y, Bruegel M, Ceglarek U, Fiers T, Gaudl A, Kurka H, Milczynski C, Prat Knoll C et al. Multicenter performance evaluation of a second generation cortisol assay. Clinical Chemistry and Laboratory Medicine 201755 826-835. (https://doi. org/10.1515/cclm-2016-0400)

24 Methlie P, Hustad SS, Kellmann R, Almas B, Erichsen MM, Husebye E \& Lovas K. Multisteroid LC-MS/MS assay for glucocorticoids and androgens, and its application in Addison's disease. Endocrine Connections 20132 125-136. (https://doi.org/10.1530/EC-13-0023)

25 Ueland GÅ, Methlie P, Kellmann R, Bjorgaas M, Asvold BO, Thorstensen K, Kelp O, Thordarson HB, Mellgren G, Lovas K et al. Simultaneous assay of cortisol and dexamethasone improved diagnostic accuracy of the dexamethasone suppression test. European Journal of Endocrinology 2017176 705-713. (https://doi.org/10.1530/ EJE-17-0078)

26 Ceccato F, Antonelli G, Frigo AC, Regazzo D, Plebani M, Boscaro M $\&$ Scaroni C. First-line screening tests for Cushing's syndrome in patients with adrenal incidentaloma: the role of urinary free cortisol measured by LC-MS/MS. Journal of Endocrinological Investigation 2017 40 753-760. (https://doi.org/10.1007/s40618-017-0644-8)
27 Kidambi S, Raff H \& Findling JW. Limitations of nocturnal salivary cortisol and urine free cortisol in the diagnosis of mild Cushing's syndrome. European Journal of Endocrinology 2007 157 725-731. (https://doi.org/10.1530/EJE-07-0424)

28 Ploeger B, Mensinga T, Sips A, Deerenberg C, Meulenbelt J \& DeJongh J. A population physiologically based pharmacokinetic/ pharmacodynamic model for the inhibition of 11-betahydroxysteroid dehydrogenase activity by glycyrrhetic acid. Toxicology and Applied Pharmacology 2001170 46-55. (https://doi. org/10.1006/taap.2000.9078)

29 Methlie P, Husebye EE, Hustad S, Lien EA \& Lovas K. Grapefruit juice and licorice increase cortisol availability in patients with Addison's disease. European Journal of Endocrinology 2011165 761-769. (https:// doi.org/10.1530/EJE-11-0518)

30 Xiao YJ, Hu M \& Tomlinson B. Effects of grapefruit juice on cortisol metabolism in healthy male Chinese subjects. Food and Chemical Toxicology 201474 85-90. (https://doi.org/10.1016/j.fct.2014.09.012)

31 Ma X, Lian QQ, Dong Q \& Ge RS. Environmental inhibitors of 11ß-hydroxysteroid dehydrogenase type 2. Toxicology 2011285 83-89. (https://doi.org/10.1016/j.tox.2011.04.007)

32 Ferrari P, Sansonnens A, Dick B \& Frey FJ. In vivo 11beta-HSD-2 activity: variability, salt-sensitivity, and effect of licorice. Hypertension 200138 1330-1336. (https://doi.org/10.1161/hy1101.096112)

33 Kivlighan KT, Granger DA, Schwartz EB, Nelson V, Curran M \& Shirtcliff EA. Quantifying blood leakage into the oral mucosa and its effects on the measurement of cortisol, dehydroepiandrosterone, and testosterone in saliva. Hormones and Behavior 200446 39-46. (https:// doi.org/10.1016/j.yhbeh.2004.01.006)

34 Palermo M, Shackleton CH, Mantero F \& Stewart PM. Urinary free cortisone and the assessment of 11 beta-hydroxysteroid dehydrogenase activity in man. Clinical Endocrinology $1996 \mathbf{4 5}$ 605-611. (https://doi.org/10.1046/j.1365-2265.1996.00853.x)

$35 \mathrm{Ng}$ CM, Lam TK, Au Yeung YC, Choi CH, Iu YP, Shek CC \& Tiu SC. Clinical utility of late-night and post-overnight dexamethasone suppression salivary cortisone for the investigation of Cushing's syndrome. Hong Kong Medical Journal 201723 570-578. (https://doi org/10.12809/hkmj176240)

36 Raff H \& Phillips JM. Bedtime salivary cortisol and cortisone by LC-MS/MS in healthy adult subjects: evaluation of sampling time. Journal of the Endocrine Society 20193 1631-1640. (https://doi. org/10.1210/js.2019-00186)

37 Lac G \& Chamoux A. Do circannual rhythm of cortisol and testosterone interfere with variations induced by other events? Annales d'Endocrinologie 200667 60-63. (https://doi.org/10.1016/ s0003-4266(06)72542-2)

38 Melin EO, Thunander M, Landin-Olsson M, Hillman M \& Thulesius HO. Depression, smoking, physical inactivity and season independently associated with midnight salivary cortisol in type 1 diabetes. BMC Endocrine Disorders 201414 75. (https://doi. org/10.1186/1472-6823-14-75)

39 King JA, Rosal MC, Ma Y, Reed G, Kelly TA, Stanek 3rd EJ \& Ockene IS. Sequence and seasonal effects of salivary cortisol. Behavioral Medicine 200026 67-73. (https://doi. org/10.1080/08964280009595753)

40 Thorn L, Evans P, Cannon A, Hucklebridge F \& Clow A. Seasonal differences in the diurnal pattern of cortisol secretion in healthy participants and those with self-assessed seasonal affective disorder. Psychoneuroendocrinology 201136 816-823. (https://doi. org/10.1016/j.psyneuen.2010.11.003)

41 Matchock RL, Dorn LD \& Susman EJ. Diurnal and seasonal cortisol, testosterone, and DHEA rhythms in boys and girls during puberty. Chronobiology International 200724 969-990. (https://doi. org/10.1080/07420520701649471)

42 Adamsson M, Laike T \& Morita T. Annual variation in daily light exposure and circadian change of melatonin and cortisol concentrations at a northern latitude with large seasonal differences 
in photoperiod length. Journal of Physiological Anthropology 201636 6. (https://doi.org/10.1186/s40101-016-0103-9)

43 Wirtz PH, von Kanel R, Emini L, Ruedisueli K, Groessbauer S, Maercker A \& Ehlert U. Evidence for altered hypothalamuspituitary-adrenal axis functioning in systemic hypertension: blunted cortisol response to awakening and lower negative feedback sensitivity. Psychoneuroendocrinology 200732 430-436. (https://doi. org/10.1016/j.psyneuen.2007.02.006)

44 Liu H, Bravata DM, Cabaccan J, Raff H \& Ryzen E. Elevated latenight salivary cortisol levels in elderly male type 2 diabetic veterans. Clinical Endocrinology 200563 642-649. (https://doi.org/10.1111/ j.1365-2265.2005.02395.x)

45 Badrick E, Kirschbaum C \& Kumari M. The relationship between smoking status and cortisol secretion. Journal of Clinical Endocrinology and Metabolism 200792 819-824. (https://doi.org/10.1210/jc.20062155)

46 Miller R, Stalder T, Jarczok M, Almeida DM, Badrick E, Bartels M, Boomsma DI, Coe CL, Dekker MC, Donzella B et al. The CIRCORT database: reference ranges and seasonal changes in diurnal salivary cortisol derived from a meta-dataset comprised of 15 field studies. Psychoneuroendocrinology 201673 16-23. (https://doi.org/10.1016/j. psyneuen.2016.07.201)

47 Alwani RA, Schmit Jongbloed LW, de Jong FH, van der Lely AJ, de Herder WW \& Feelders RA. Differentiating between Cushing's disease and pseudo-Cushing's syndrome: comparison of four tests. European Journal of Endocrinology 2014170 477-486. (https://doi.org/10.1530/ EJE-13-0702)
48 Leproult R, Copinschi G, Buxton O \& Van Cauter E. Sleep loss results in an elevation of cortisol levels the next evening. Sleep 199720 865-870. (https://doi.org/10.1093/sleep/20.10.865)

49 Raff H, Raff JL, Duthie EH, Wilson CR, Sasse EA, Rudman I \& Mattson D. Elevated salivary cortisol in the evening in healthy elderly men and women: correlation with bone mineral density. Journals of Gerontology: Series A, Biological Sciences and Medical Sciences 199954 M479-M483. (https://doi.org/10.1093/gerona/54.9.m479)

50 Sharma ST, Nieman LK \& Feelders RA. Cushing's syndrome: epidemiology and developments in disease management. Clinical Epidemiology 20157 281-293. (https://doi.org/10.2147/CLEP. S44336)

51 Nickelsen T, Lissner W \& Schoffling K. The dexamethasone suppression test and long-term contraceptive treatment: measurement of ACTH or salivary cortisol does not improve the reliability of the test. Experimental and Clinical Endocrinology 198994 275-280. (https://doi.org/10.1055/s-0029-1210910)

52 Qureshi AC, Bahri A, Breen LA, Barnes SC, Powrie JK, Thomas SM \& Carroll PV. The influence of the route of oestrogen administration on serum levels of cortisol-binding globulin and total cortisol. Clinical Endocrinology 200766 632-635. (https://doi.org/10.1111/j.13652265.2007.02784.x)

53 Simunkova K, Starka L, Hill M, Kriz L, Hampl R \& Vondra K. Comparison of total and salivary cortisol in a low-dose ACTH (Synacthen) test: influence of three-month oral contraceptives administration to healthy women. Physiological Research $2008 \mathbf{5 7}$ (Supplement 1) S193-S199.

Received 29 October 2019

Revised version received 4 March 2020

Accepted 26 March 2020 